\title{
NOTES ON THE LIFE CYCLE AND NATURAL HISTORY OF \\ DISMORPHIA VIRGO (LEPIDOPTERA: PIERIDAE: DISMORPHIINAE) IN COSTA RICA*
}

\author{
By Allen M. Young \\ Department of Biology, Lawrence University \\ Appleton, Wisconsin 549I I
}

This paper summarizes the life cycle and some aspects of natural history of the tropical pierid, Dismorphia virgo (Dismorphiinae) in Costa Rica. The precise taxonomic status of the butterfly in Central America has not been established, and it may represent a variable northern isolate of the common South American D. critomedia. Therefore, independent of whether the Central American form discussed in this paper has achieved full species status as the more northern virgo or is a subspecies or variety of critomedia, evolving towards species status, this paper provides new information on the biology of the butterfly in Costa Rica. The establishment of precise taxonomic position awaits further study, and for the present purpose, I refer to the butterfly as $D$. virgo.

\section{METhods}

Field observations were conducted during June-September 197 I at two localities in the central Cordillera ("Meseta Central") of Costa Rica: (I) Bajo la Hondura (San José Province) on the Pacific side, and (2) Cuesta Angel (Heredia Province) on the Caribbean side. Both localities are characterized by montane tropical wet forest (800-1000 m elev.). Observations, including searches for larval host plants, were made in forest clearings associated with paths and river edges. A total of 32 days were spent in field observation at Bajo la Hondura and 27 days were spent at Cuesta Angel; both localities were never visited the same day. Since many days were spent studying $D$. virgo at each locality, it was possible to obtain quantitative information in the sense of making repeated observations under known field conditions. Furthermore, usually between 4 and 6 hours were spent daily in the field.

Observations or field studies consisted of: (I) description of life cycle, including recording of host plants and estimation of developmental time, (2) studies of larval behavior, and (3) studies of adult behavior.

*Manuscript received by the editor September 14, 1972 
Life cycle and developmental time were studied using two approaches: (I) bagging of recently oviposited eggs on host plants in the field, and (2) rearing of eggs in the laboratory. The laboratory was located in San José, with diurnal room temperature conditions ranging between $25-29^{\circ} \mathrm{C}$, a condition comparable to the temperature regime at both localities. The laboratory approach, which involved keeping cultures in tightly closed clear plastic bags, gave more accurate estimates of developmental time because life stages could be observed more readily.

Studies of larval behavior dealt with feeding and defense activities of larvae on host plants in the field. Studies of adult behavior dealt with oviposition and mimcry. Populations of potential members of mimicry complexes involving $D$. virgo were sampled for a number of successive days each month (July and August) at both Bajo la Hondura and Cuesta Angel. A sample on a given day at each locality was taken by walking along a foot path for a distance of about I50 meters (Cuesta Angel) or 200 meters (Bajo la Hondura). The basic technique was to walk about 5 meters, look for butterflies, and repeat this procedure for the entire transect, recording the species seen within each 5-meter interval. At both localities, this procedure lasted about one hour daily, and samples were usually taken at 9:30-10:30 A.M. (C. S. T.). Collecting in each area prior to sampling gave an indication of the species to be considered in gathering quantitative data on mimcry complexes.

\section{Life cycle and developmental time}

\section{RESULTS}

The thin, spindle-shaped $(1.5 \times 0.7 \mathrm{~mm})$ eggs are laid singly on the undersides of young or old leaves of Inga pittieri (Killip) (Leguminosae) at both localities. Each egg (Fig. I-A) is at first satiny-white, but within a few hours turns a light blue-green color; each egg has 8 ribs. Immediately prior to hatching, the egg turns yellow.

The first instar is translucent yellow throughout, bearing a sparse covering of fine hairs and is about $2.2 \mathrm{~mm}$ long upon hatching. The first instar also bears one pair of posterior and one pair of anterior elongated black hairs which are lost in later instars; these projections are barely visible in Fig. I-B. By the first molt, the larva is about $5.2 \mathrm{~mm}$ long and appears dark green due to undigested plant material in the digestive tract. The second instar (Fig. I-C) is very similar in appearance to the first instar. The body is light green throughout. The larva measures about $10 \mathrm{~mm}$ in length by the time 

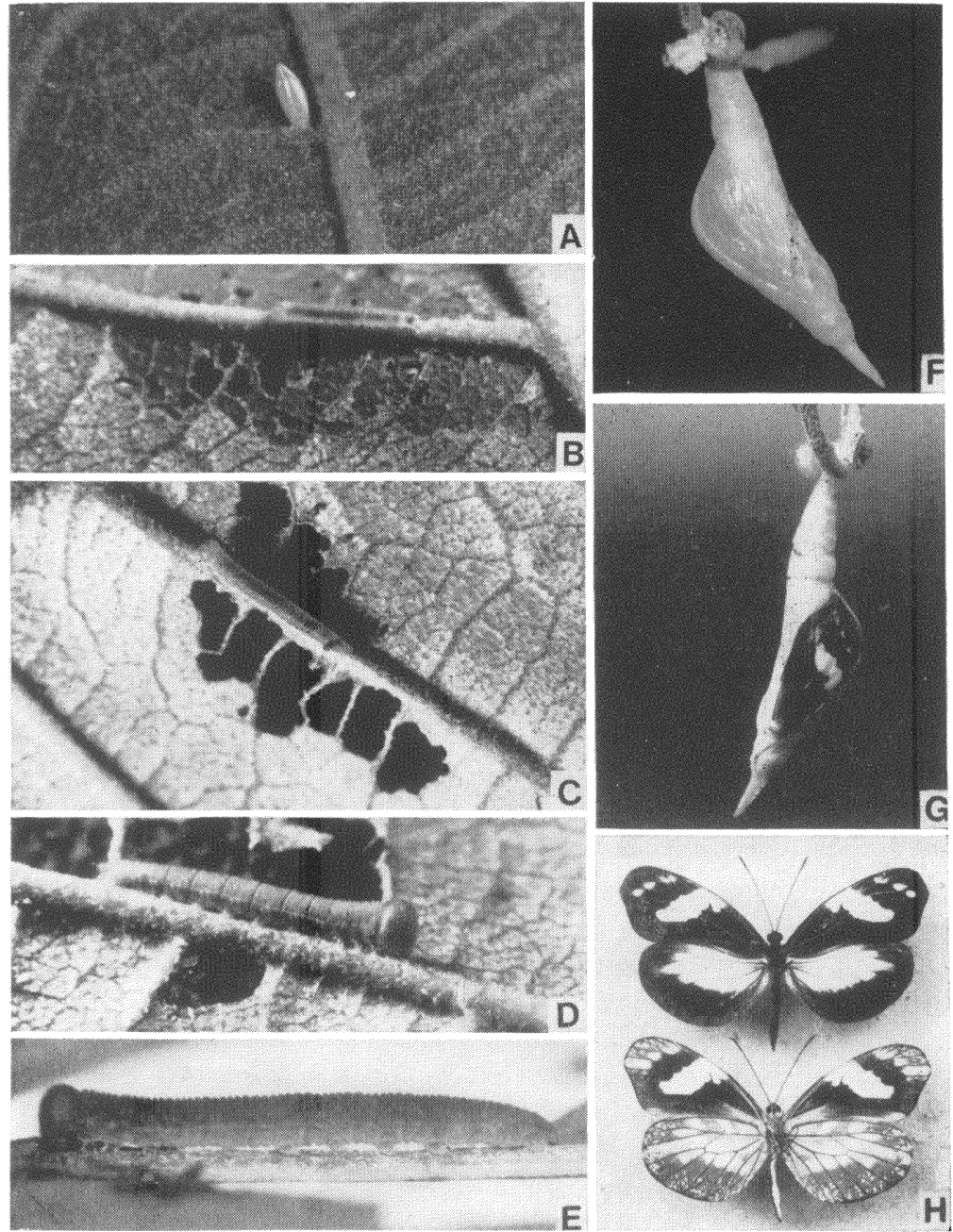

Fig. 1. The life cycle of Dismorphia virgo: egg (A), instars 1, 2, 4, 5 respectively (B-E), pupa (F-G), and adult females $(H)$. 
of the second molt. The third instar has the head, anal region, and prolegs a dull orange color and body uniformly green.

The body is covered by sparse hair. The larva is about $14 \mathrm{~mm}$ long at the third molt. The fourth instar (Fig. I-D) is uniformly dark green throughout the head, body, anal region, and prolegs. The head and body are covered by a dense down of short red hairs. The head is now noticeably wider than the body, which tapers towards the anal region. At the time of the fourth molt, the larva is about $20 \mathrm{~mm}$ long. The fifth (final) instar (Fig. I-E) is very similar to the previous instar, but the head is gray-green and the spiracles are bordered in red. Both head and body retain the dense reddish down seen in the previous instar. The larva measures about $28 \mathrm{~mm}$ in length by pupation.

Until the day preceding eclosion, the elongate pupa (Fig. I-F) remains light green; after this, the pupa darkens and the wing-pattern becomes visible (Fig. $\mathrm{I}-\mathrm{G}$ ). The pupa is about $2 \mathrm{I} \mathrm{mm}$ long. Sexual dimorphism in wing coloration is pronounced; Fig. $\mathrm{I}-\mathrm{H}$ shows the dorsal and ventral aspects of a female. The large light dorsal forewing areas are yellow in females and white in males (and reduced), and the distal series of three small spots of the female are cream. In the female, the large light area on the dorsal surface of each hindwing is bright yellow, while in the male this area is larger and whitish. Ventral markings of both sexes are remarkably similar. The forewing length of wild-caught (Io individuals) adults is $29.4 \pm 1.2 \mathrm{~mm}$. It should be emphasized that the lighter dorsal regions of the wings are not creamy-white, which is characteristic of $D$. virgo. The wings of females bear a yellow color very similar to that of a sympatric ithomiid, Oleria zelica pagasa (see below).

As commonly noted in butterflies, developmental time is strongly affected by whether larvae feed on young or old leaves (Table I). The leaves of the larval host plant are of two kinds: ( I) tough, older green leaves, and (2) soft, young red leaves at the apex of the plant. Eggs are found in the field on both kinds of leaves, but usually not on older leaves when young leaves are present on an individual plant. The individual host plants studied at Cuesta Angel did not have young leaves during the study period, whereas extensive flushes of young leaves were found on several individual plants at Bajo la Hondura, but only after the middle of July. Individuals reared on young leaves of $I$. pittieri complete development sooner than individuals reared on older leaves (Table 1 ). This effect of leaf age is significant, as indicated by a $t$ test $(\mathrm{P}<0.05)$. The individuals used to measure this effect were obtained from eggs seen 
oviposited in the field on young or old leaves. Developmental time on both young and old leaves was similar (no significant differences with $t$ test) between the field and laboratory.

At Bajo la Hondura, I. pittieri is most abundant along exposed river edges where it is a member of young second-growth plant communities. At Cuesta Angel, the plant is a member of the heavily shaded forest understory. At both localities the plant grows as a small woody tree, usually $\mathrm{I} .5$ to $4.0 \mathrm{~m}$ in height. Different annual patterns of leafing out may be a function of the type of plant community in which the tree is found. Leafing out may have a different pattern at Cuesta Angel than it does at Bajo la Hondura, a factor influencing the egg laying habits of $D$. virgo and in turn, the developmental time in different populations at various times of the year.

\section{Larval Behavior}

Perhaps the most interesting feature of the behavior of larval $D$. virgo is their apparent crypsis, both in morphology (coloration and form) and behavior (resting positions on the host plant). The larvae are thin and green and very difficult to find on the plant. The concealment is enhanced by their ventral positions on leaves and their use of large veins as resting sites (Fig. I-B, C, D). This combination of morphological and behavioral crypsis might function to reduce attacks by predators and parasites. Of a total of 13 young larvae (6 first instar, 3 second instar, I third instar, and 3 fourth instar) observed at Bajo la Hondura during late July and early August, on tagged host plants, all of these survived to the late fifth instar. Although this sample is small, the data suggest low predation and parasitism on larvae; fates of fifth instar searching for pupation sites and pupae in the field were not determined. Egg mortality has not been studied. Furthermore, since observations on larval mortality were confined to a relatively small portion of the year, it is not known if predation rates on larvae in this butterfly vary seasonally.

Although as many as 5 eggs might be oviposited at different spots on a single leaf, larvae are never gregarious. When eggs are laid on older leaves, larvae feed at the edges and work their way inward as they grow larger. When eggs are laid on young leaves, larvae may begin to feed immediately on inner portions of the leaf. On older leaves, first instars can only eat part way through the leaf. On young leaves, first instars can eat all the way through the leaf tissue. Such a difference in feeding may affect the rate of food assimilation by the young larvae, thereby increasing or decreasing the 
length of first and second instars (Table $\mathrm{I}$ ). Such a difference in growth between larvae on new and old leaves can be due to both the amount of feeding and digestibility. Larvae usually do not devour their empty egg shells, although they do eat cast exuviae at molts. Both in the field and laboratory, feeding is greatest at night, suggesting further the possibility of crypsis as a protective strategy.

Pupation generally occurs away from the host plant, and frequently on stems and leaves of herbaceous plants near the ground.

Adult Behavior

Since adult population densities appear to be exceedingly low, it is very difficult to obtain quantitative data on behavioral patterns, especially those associated with oviposition, feeding, home range movements, etc. Of these various kinds of behavior, oviposition was the easiest to observe during the study period.

Oviposition occurred throughout the day at both localities. The usual pattern observed is that a female patrols an individual host plant several times, pausing to lay several eggs. If the plant bears young red leaves, these are always selected for oviposition; otherwise, eggs are laid on old green leaves. In both cases, the female alights near the dorsal edge of a leaf, crawls to the ventral edge, and oviposits. On older leaves, however, eggs are attached at the very edge of the leaf; the female will lay one egg, walk along the edge, lay another, and repeat this behavior several times. Usually between I-5 eggs may be oviposited along a single edge of a large leaf. During July and August representing a portion of the wet season, cloud cover generally persists throughout the day, and occurs every day; nevertheless, oviposition occurs on such cloudy days. It is curious that females do not lay eggs along the opposite edges of the same leaf. If on a young red leaf, the female walks to the inner regions of the ventral surface, where she oviposits one to several eggs, each attached to a small vein (Fig. I-A). Eggs were rarely found along the edges of young red leaves. After ovipositing several times on a single leaf the female may continue to patrol the same plant, pausing to oviposit on other leaves.

After several oviposition sequences at a plant, the female flies away, perhaps in search of other plants. Oviposition has not been observed on other plant species at either locality, despite observations on flying activity of adults in forest understory, second-growth, etc. I. pittieri might be the only host plant of this butterfly at both localities. Since adults seem very vagile, it is possible that the breeding population is highly dispersed, in response to the apparent rarity of individuals of $I$. pittieri. 
At Cuesta Angel, it was observed that males often patrol regular areas along a foot trail leading down to a river through steep primary-growth forest. Although these individuals (a total of 6 patrolling sites were discovered during July and August) were not marked, there is high site tenacity since the males were seen on several successive days. Although courtship was not observed either at these patrolling sites or at host plants, such a dispersed population of $D$. virgo may have a courtship strategy in which males patrol well established sites for females, as a mechanism for bringing virgin females in contact with males. The six male-patrolling sites at Cuesta Angel were widely separated from each other with the least distance between two of them being about 100 meters.

At both locailities, adult $D$. virgo co-occurs in the same habitat as unrelated species which bear mimetic resemblance to it (Table 2). At Banjo la Hondura, the additional species is Oleria zelica pagasa (Druce) (Nymphalidae: Ithomiinae), and at Cuesta Angel, $O$. zelica pagasa and female Itaballia caesia tenuicornis (Butler \& Druce) (Pieridae: Pierinae) (Fig. 2). All three species are similar in wing-length and bear a similar black and lemon-yellow color pattern on the dorsal wing surfaces. But the resemblance is greater between $D$. virgo and $O$. zelica pagasa than it is for either of these butterflies with $I$. caesia tenuicornis (Fig. 2). Sexual dimorphism is very pronounced in $I$. caesia tenuicornis, and only the female resembles both sexes of $O$. zelica pagasa and female $D$. virgo (Young, in prep.). While the sample size is small (Table 2) and observations were made for only a two-month period, the observed regular cooccurrence of these butterflies is suggestive of mimetic association. Verification of this hypothesis awaits further field studies on more extensive estimates of relative abundance, incidence of beak-mark impressions on wings of each species, and laboratory experimental feeding studies on palatability.

\section{Discussion}

If both sexes or at least female $D$. virgo at both localities is involved in a mimicry complex, then it is probable that this butterfly is a Batesian mimic of $O$. zelica pagasa, a species occurring at both localities. If it is assumed that mimetic association is operative between these butterflies (an assumption supported in part by the observed regular co-occurrence of these butterflies in the same habitat for at least one time of the year - Table 2), the presumed palatability of $D$. virgo, in the absence of experimental feeding studies, 


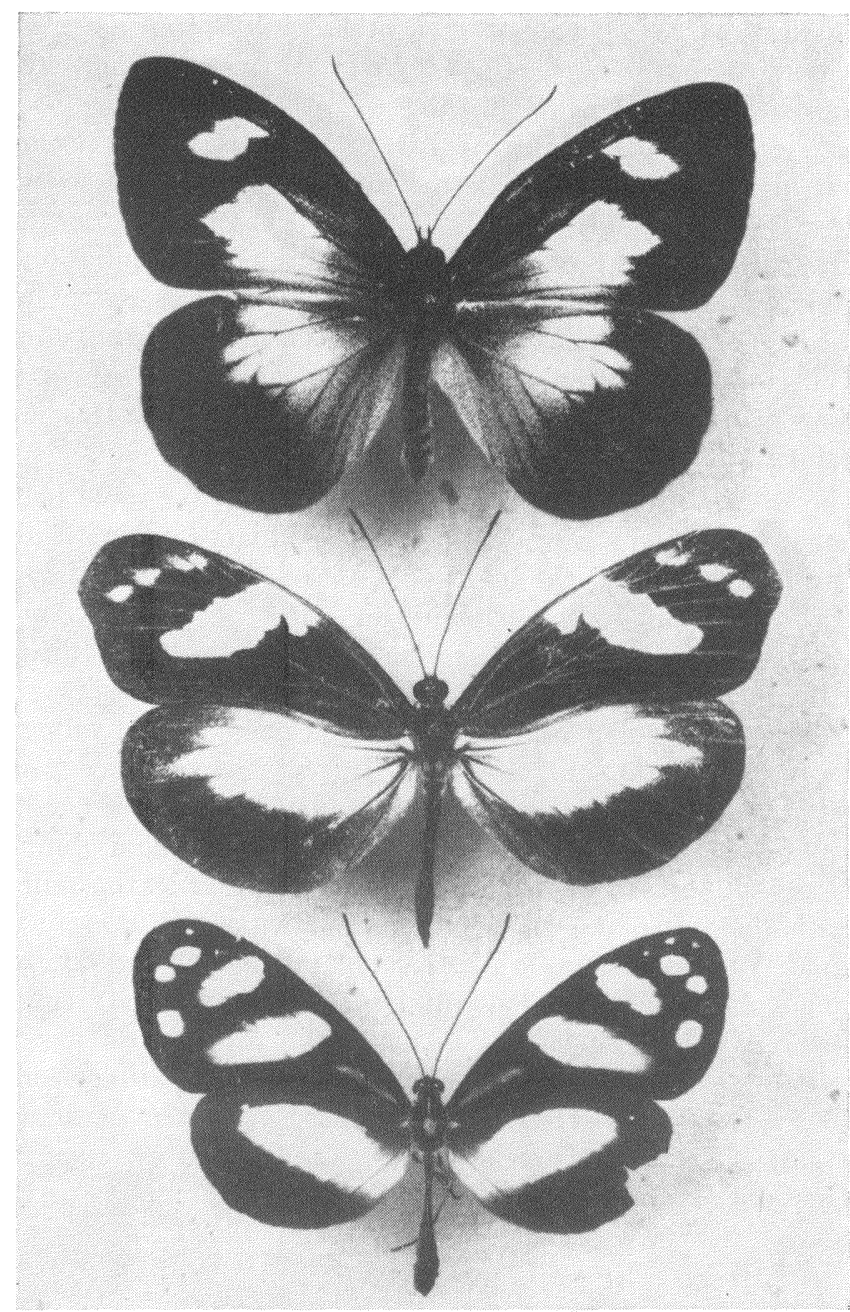

Fig. 2. Top to bottom: Itaballia caesia ( 9 ), Dismorphia virgo ( 9 ) and Oleria zelica ( + ). 
may be inferred from (I) the host plant, (2) the appearance and behavior of larvae, and (3) low adult population densities.

The genus Inga, as in other Leguminosae, is not known to contain toxic compounds (Erhlich and Raven, 1965; Levin, 1971) and it is therefore unlikely that invertebrate herbivores feeding on it would be unpalatable to potential predators. However, developmental differences in levels of various secondary compounds have not been studied in the Leguminosae, so little is known about age-specific differences in such compounds in leaves of selected genera such as Inga.

Larvae are cryptically-colored and they also behave in a cryptic manner. Such morphological and behavioral crypsis has apparently evolved as an adaptive strategy of concealment against predators. In the presence of unpalatability, it can be argued that aposematic coloration and behavior replaces crypsis as an adaptive strategy in some insects (Brower and Brower, 1964).

Of the several requisites underlying effective Batesian mimicry (see Rettenmeyer, I970), one of the most important is that the mimic always be less abundant locally than the model. However, depending on the degree of unpalatability of the model and the memory characteristics of the predators, it is possible to have mimics more abundant than models and still have effective mimicry. Thus, for a butterfly which is a Batesian mimic of an only slightly unpalatable model, low local adult population density in habitats where the model is abundant is essential. Thus, for a butterfly which is a Batesian mimic of an only slightly unpalatable model, low local adult population density in habitats where the model is abundant is essential. This property is indicated by the data in Table 2. The exploitation of a courtship strategy characterized by males patrolling specific sites on a regular basis in the habitat is also indicative of low population density in this butterfly.

Further evidence, from phylogenetic considerations, of the palatability of $D$. virgo is given by Brower and Brower ( 1964 ), who point out that the Dismorphiinae, being the most primitive subfamily of the Pieridae, are most likely palatable, since unpalatability is held to be a highly evolved trait of more advanced subfamilies.

Since the Ithomiinae are known to be a very unpalatable group of tropical butterflies (cf. Brower and Brower, 1964), there is little doubt that $O$. zelica pagasa can act as a model for $D$. virgo, if selection pressures favor the development of mimetic association at Bajo la Hondura and Cuesta Angel. The Ithomiinae presumably derive their highly reputed unpalatability from the Solanaceae (Ehrlich 


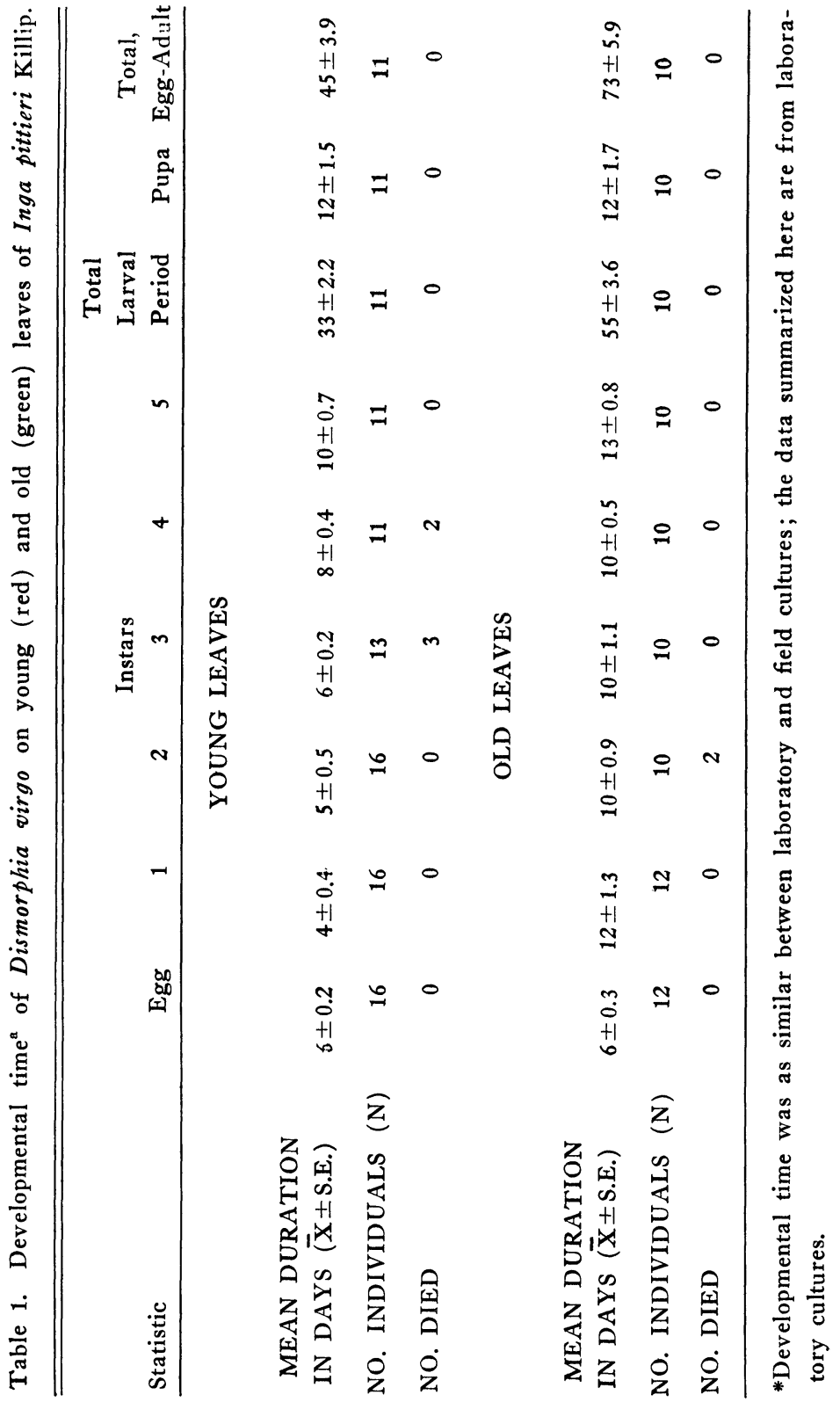


and Raven, 1965; Fraenkel, 1959), the major larval host plant family of these butterflies. The biology of $O$. zelica pagasa will be summarized later (Young, in prep.).

The possible position of $I$. caesia tenuicornis in a mimicry complex at Cuesta Angel (Table 2) is less clear at this time. It is far more abundant locally than either $D$. virgo or $O$. zelica pagasa (Table 2) during July and August. Three possibilities exist here: (I) I. caesia tenuicornis is unpalatable and bears Müllerian mimetic relation with $O$. zelica and perhaps Batesian relation to $D$. virgo, (2) I. caesia tenuicornis is palatable, at certain times of the year it is unusually abundant, and mimetic association, if any, breaks down. (Under the alternative, at other times of the year its local abundance does not exceed that of $O$. zelica pagasa and it is a Batesian mimic of that butterfly during those times.) and (3) I. caesia tenuicornis does not enter into a mimicry complex at Cuesta Angel at any time of the year. The weaker resemblance of this species to either of the other butterflies suggests that this may be the case, although more extensive field study is needed to confirm any of these alternative ideas. The major larval host plant of $I$. caesia tenuicornis at Cuesta Angel during July and August is Gynandropsis pulcherrima in the Capparidaceae (Young, in prep.), a plant family rich in mustard oil glucosides (Alston and Turner, I963). Since experimental feeding studies were not conducted, the palatability of $I$. caesia tenuicornis remains undetermined.

A final interesting point is the increased rate of development of $D$. virgo on young leaves of $I$. pittieri (Table I). In this presumably palatable butterfly, natural selection should favor oviposition on young leaves of the host plant since such behavior on the part of the female butterfly would reduce the risk of predation or parasitism on the larvae (since less time is spent in the larval stage when larvae eat young leaves). But the extent to which this adaptive mechanism is operative in populations of $D$. virgo or any palatable species depends upon the seasonal pattern of vegetative growth in the host plant population at a given locality. It is then hypothesized the rates of predation or parasitism will vary seasonally, and that such temporal differences are partly accountable through the pattern of leafing out (vegetative growth). Thus it is predicted that the local abundance of $D$. virgo depends upon the time of year and perhaps upon the type of plant community (i.e., shaded understory versus well insolated clearings and marginal habitats) since a plant species may show different physiological responses (associated with growth and maintenance) in different communities (Holdridge et 
Table 2. Relative abundance of butterflies in possible mimicry complexes at Baja la Hondura and Cuesta Angel, Costa Rica

\begin{tabular}{|c|c|c|c|c|}
\hline \multirow[b]{2}{*}{ Month } & \multirow{2}{*}{$\begin{array}{l}\text { No. successive } \\
\text { days sampled } \\
\text { (N) }\end{array}$} & \multicolumn{3}{|c|}{ Mean number of individuals seen ${ }^{b}$} \\
\hline & & D. virgo & I. Caesia & O. zelica \\
\hline \multicolumn{5}{|c|}{ Bajo la Hondura } \\
\hline July & 8 & 9 & 0 & 16 \\
\hline August & 12 & 7 & 0 & 15 \\
\hline \multicolumn{5}{|c|}{ Cuesta Angel } \\
\hline July & 10 & 10 & 44 & 18 \\
\hline August & 12 & 8 & 30 & 21 \\
\hline
\end{tabular}

asmpling was conducted for 1 hour each day; see text for further description of technique.

${ }^{b}$ Given are the mean numbers of adults (both sexes) seen at sampling sites ... per day $(9: 30-10: 30 \mathrm{AM})$

al., I97 I). While these advantages of a shortened larval period are clearly adaptive, another adaptive role of this effect is an increased reproductive fitness resulting from the shortening of the life table parameter, age-to-first reproduction. Adult females experiencing selection pressures to lay eggs on young leaves promote this advantage in life table structure of natural populations.

Changes in oviposition site-selectivity with seasonal changes in the availability of young leaves of herbivore host plants in the tropics offer an interesting system to approach the general question of how developmental changes in leaf biochemistry can alter the palatability of the herbivore, assuming that palatability is at least in part derived from host plants. If we may reach beyond the data in Table I for $D$. virgo, there exists the possibility of variation in palatability depending on whether or not it underwent larval development on old or young leaves of the host plant. Depending on the time of year and a host of local edaphic factors which affect the vegetative growth pattern of the host plant, a herbivore population may vary tremendously in the proportion of palatable and unpalatable individuals. This, of course, assumes that differences in toxicity occur between young and old leaves within a plant population. Recent discussion (Levin, 197I) indicates that there can occur both quanti- 
tative and qualitative differences in secondary compounds between young and old parts of plants. This question is raised here in a speculative manner since the primary selective advantage of laying eggs on young leaves (when available), which is known to occur in many species of butterflies, may have other ecological consequences bearing on the problem of labelling a species as "palatable" or "unpalatable".

\section{SUMMARY}

(I) The life cycle, larval host plant, and developmental time of Dismorphia virgo are reported for the first time.

(2) Breeding populations of the butterfly exploit the same larval host plant, Inga pittieri (Leguminoseae), at two different mountain localities in central Costa Rica.

(3) The developmental time of $D$. virgo on old leaves of the host plant is about 73 days, while on young leaves it is about 45 days, a significant reduction in this ecological statistic.

(4) There is selection for oviposition on young leaves when these become available in a habitat. The availability of young leaves in a given habitat is probably dependent upon local edaphic and ecological factors and may vary considerably among different geographic regions. Such oviposition-site selectivity may be selected for in populations of palatable butterflies since it results in a reduced risk of predation or parasitism since the insect spends less time as a larva. But since many tropical plants have seasonal vegetative growth patterns which vary within species in different habitats, it is hypothesized that any observable changes in predation or parasitism rates in the herbivore population are partly accountable in terms of these patterns.

(5) The regular co-occurrence (at least for July and August) of adult $D$. virgo with other butterflies which resemble the female to some degree suggests the possibility of the existence of a mimicry complex at each locality studied. The butterfly may be a Batesian mimic of the ithomiid, Oleria zelica pagasa which occurs at each locality; $D$. virgo is less abundant than $O$. zelica pagasa at each locality. The presumed palatability of $D$. virgo is suggested by its larval host plant, the cryptic appearance and behavior of the larvae, and the very low population density. At one locality, Cuesta Angel, a third butterfly, the pierid Itaballia caesia tenuicornis, may also enter the mimicry complex, although it bears less mimetic resemblance to the other two butterflies. It is very abundant during July and Au- 
gust (and maybe at other times of the year) and this may be a further indication of its non-participation in the mimicry complex.

(6) From observations of selective advantage associated with oviposition on young leaves of host plants by herbivorous insects, including butterflies, it is suggested that an interesting question to be investigated is the possibility of the occurrence of a shifting palatability spectrum within a local insect population, which oscillates between different levels of palatability at different times of the year. Such a hypothesis assumes differences in the leaf compounds which endow the palatability properties of a species, between young and old leaves of the host plant in question, and also assumes that insects obtain their palatability at least in part from their host plants.

\section{ACKNowledgements}

This research was supported through a College Science Improvement Grant (GY-47II) awarded to Lawrence University. I was assisted in the field and laboratory by Patrick Eagan (Lawrence). The Associated Colleges of the Midwest in San Jose provided laboratory facilities and logistic support. Luis Diego Gomez (Museo Nacional de Costa Rica) identified the larval host plant.

Alston, R. E., And B. L. Turner

\section{Literature Cited}

1963. Biochemical systematics. Prentice-Hall, Englewood Cliffs, N. J. Brower, L. P., AND J. V. Z. Brower

1964. Birds, butterflies, and plant poisons: a study in ecological chemistry. Zoologica 49: 137-159.

EhrLICH, P. R., AND P. H. RAVEN

1965. Butterflies and plants: a study in coevolution. Evolution 18: 586-608.

Fraen Kel, G.

1956. Insects and plant biochemistry. The specificity of food plants for insects. Proc. 14th Inst. Congr. Zool., p. 383-387.

Holdrige, L. R., W. C. Grenke, W. H. Hatheway, T. Liang, and J. A. Tosi, JR.

1971. Forest environments in tropical life zones. Pergamon Press, Inc., Elmsford, New York.

Levin, D. A.

1971. Plant phenolics: an ecological perspective. Amer. Natur. 105: 157-181.

RETTENMEYeR, C. W.

1970. Insect mimicry. Ann. Rev. Entomol. 15 : 43-74. 

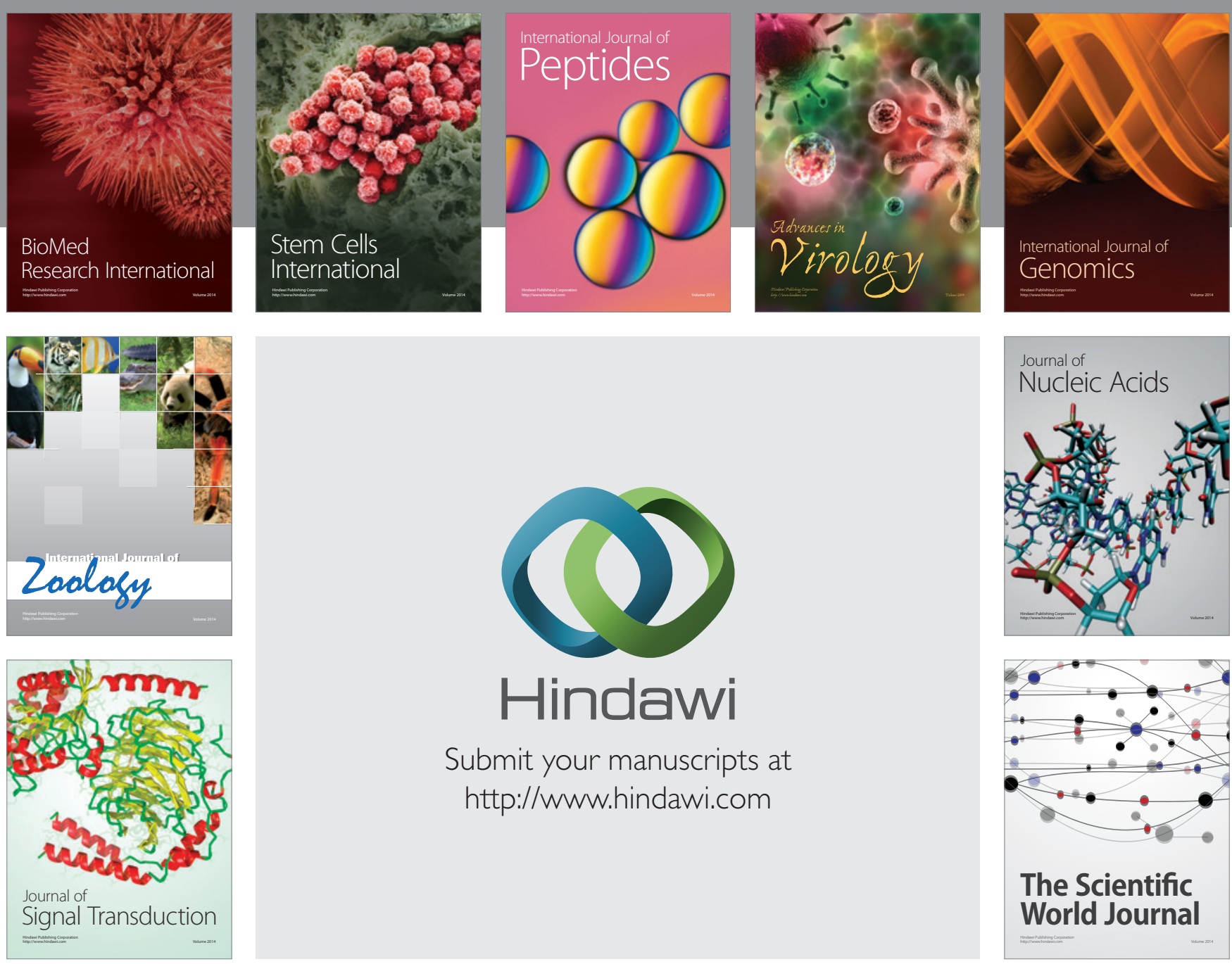

Submit your manuscripts at

http://www.hindawi.com
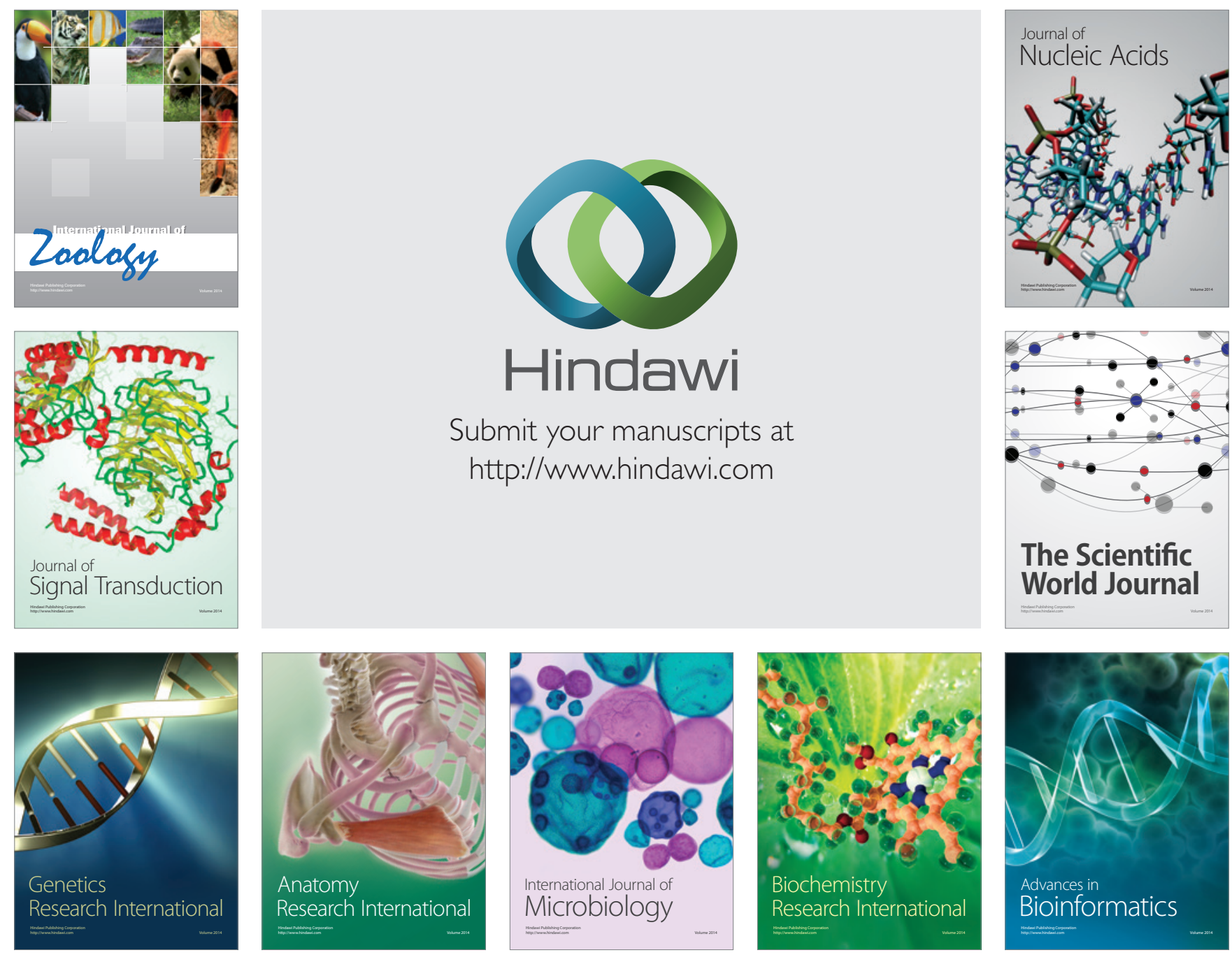

The Scientific World Journal
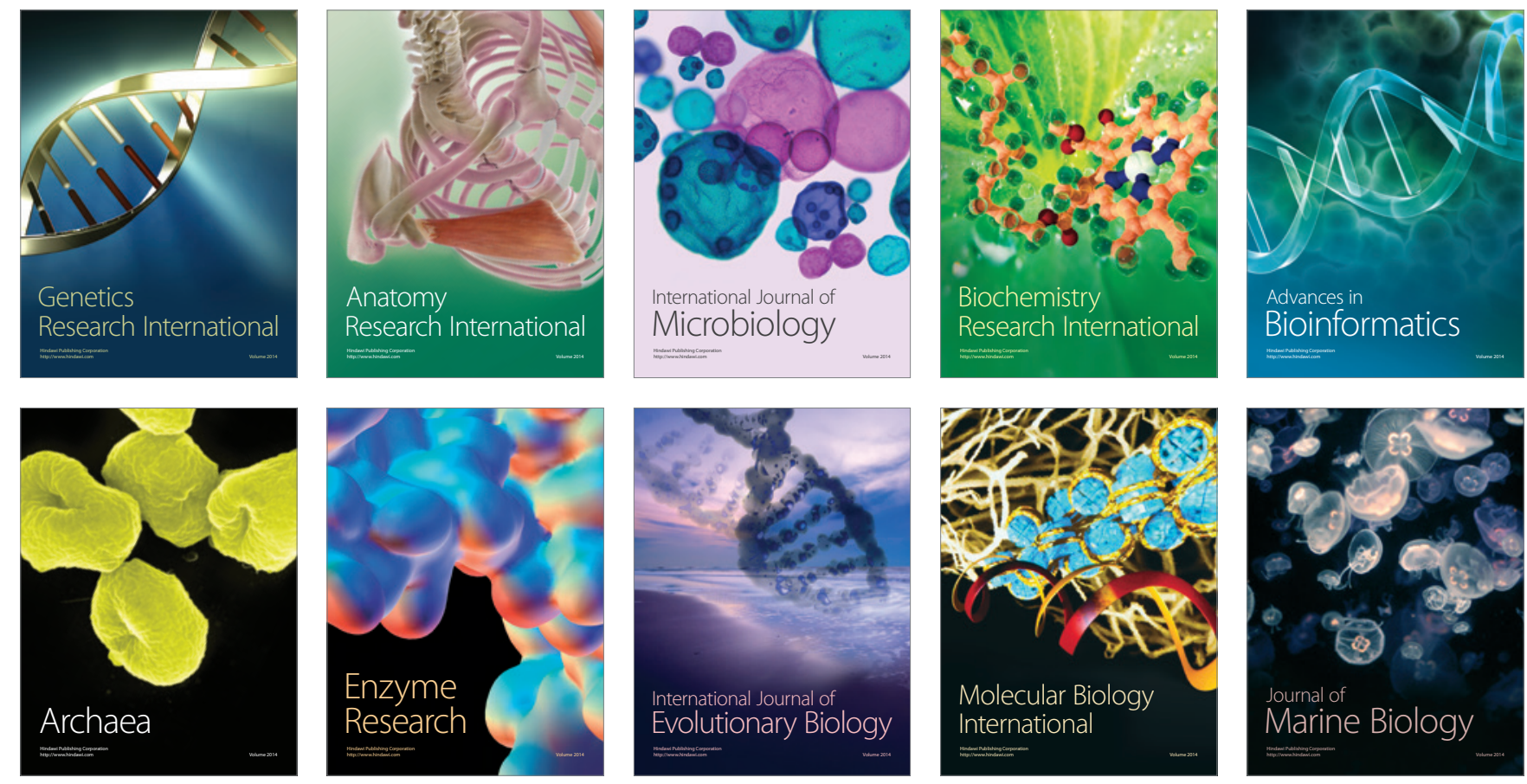